\title{
Supporting Information Technology Teachers through Programming Professional Development: A South African Case Study
}

\author{
Desmond Wesley Govender, Irene Govender, Betty Breed, Marietjie Havenga, Elsa Mentz, \\ Frank Dignum and Virginia Dignum \\ University of KwaZulu-Natal, Durban, South Africa, 4001 \\ North West University, Potchefstroom, South Africa, 2520 \\ University of Utrecht, Netherlands \\ Delft University of Technology, Netherlands
}

KEYWORDS Pair Programming. Problem Solving. Meta-cognition. Intervention Programme. Teaching Programming

\begin{abstract}
Currently, there are many challenges of preparing and supporting secondary school Information Technology (IT) teachers. In addition to increasing the number of IT teachers, there is a need of supporting those teachers to grow and to retain them as committed, quality teachers. This paper focuses on ways of supporting IT teachers through an intervention programme that supports and enriches teachers specifically in an area that poses most difficulties - programming. A case study of six teachers was used to explore the programme of intervention and determine the viability for future expansion to include more teachers in this form of professional development. Results indicate that teachers gained confidence in teaching programming and were willing to continue with the strategies in the future.
\end{abstract}

\section{INTRODUCTION}

Few schools offer Information Technology (IT) in previously disadvantaged areas in the South African context (Downes and Looker 2011). Furthermore, those that do offer IT lack professional development (PD) specifically in IT. Educational reform places high demands on student learning and the schools are held accountable for student performance. Because teachers are in a crucial place for facilitating good learning and teaching, professional development is central to accomplish the intentions of improved student performance. Several studies (for example, Marrongelle et al. 2013; Harris et al. 2012; Horsley et al. 2010; Desimone 2009; Smith 2009) have demonstrated that PD can enrich teachers' knowledge and skills and improve their attitudes towards preparation for teaching and their overall self-efficacy (Govender and Govender 2012).

While some efforts (Hasni and Lodhi 2011) are being made to prepare IT teachers in training, few are being made to support IT teachers who are already in practice to help them improve and grow. Some of the challenges facing the IT

Address for correspondence:

Desmond Wesley Govender,

Private Bag X03,

Ashwood, 3605, South Africa,

Telephone: 27031 4018977/2603428,

Fax: 0865176317,

E-mail: govenderd50@ukzn.ac.za teacher-profession are: teacher retention -many teachers leave the profession within a few years inevitably causing a high turnover of IT teachers, some teachers are resistant to change and some do not have the necessary skill to teach IT effectively, amongst other challenges (Mentz et al. 2012). The researchers challenge was how do we support these teachers, in these circumstances. The Department of Education (Department of Education 2007) recognizes the need for professional teacher development, specifically in scarce areas such as Mathematics, Science and ICT (ICT in this paper refers to IT). The researchers therefore developed an intervention programme to support six teachers in previously disadvantaged schools. Because IT covers a wide range of aspects, the programme specifically targeted one niche area of most concern to IT teachers that is programming. Programming requires a high level of cognitive ability and therefore poses difficulties in finding effective ways of teaching high school learners (Ismail et al. 2010).

\section{Literature Review}

There is a tendency to cloud the study of IT as a scientific discipline with other uses of ICT particularly within education, such as computer literacy (the mastery of basic computer skills), keyboarding, or educational technology and Technology education (Gal-Ezer and Stephenson 
2010). As a result, many administrators, and some computing teachers are not in a position to offer or expose students to the core of the academic discipline, IT. Given the rapid change in technology and developments in IT, teachers have to update their IT content knowledge and related technology used in teaching IT. Because computing education is a relatively young field of research, not much is known about best teaching practices for IT. Besides, since there are so few IT teachers - in fact one in each school if IT is being offered - these teachers are often alone with no-one close by to ask for support with regard to the content or pedagogical content knowledge (PCK) of IT. Therefore, in addition to initial teacher preparation, there is a critical need for support for in-service teachers through professional development. Indeed, this support is even more critical in the previously disadvantaged areas of the provinces where this study was carried out. It is argued that any intervention PD program that may be implemented, has at least three common intentions; namely, improved teacher learning, improved classroom practice and improved student learning (Paik et al. 2011). Furthermore, Desimone (2009) proposes that PD programs should have five core features in order for it to be effective. These features are content focus, active learning, sustained duration, coherence and collective participation.

While the review of the literature indicates that PD is needed in most disciplines, what comprises the PD program or intervention is more important for effectiveness. The emphasis of aspects to be included depends on the needs of the teachers and may vary from teacher to teacher, educational needs of the learner population and contextual background of learners (Avalos 2011). There is a constant need to experiment and reflect when dealing with PD, as it is offered in the South African context. While PD in its generic form is useful, the specific content and PCK of the subject has proven to be critical. There is no doubt that programming carries a high cognitive load (Govender et. al. 2012) and it involves skills such as problem solving, testing, debugging and troubleshooting, and abstraction and mathematical logic (Saeli et al. 2011). Indeed, computer programming and problem solving are synonymous; one cannot refer to programming without regard to problem solving. It has been shown that programming is not only difficult to learn at secondary school and tertiary levels, it is also diffi- cult to teach programming, particularly in the object oriented paradigm. Anecdotal evidence suggests that many teachers do not teach problem solving techniques explicitly or engage their learners in problem solving (Govender 2007); more time is accorded to the syntax of the programming language. It is to this end that the researchers focussed the intervention program specifically on programming. According to Glazer et al. (2005), they believe that PD for teachers should be continuing and stressed that the support provided by the PD program should be organized in a manner so that it can be delivered to teachers in their normal school day. In a later study, Lawless and Pellegrino (2007) concurred with the provision of on-going support and claimed that infrequent once-off sessions are ineffectual. Moreover, Hinson et al. (2006) argue that teacher professional development has to go beyond a concentrated forum method and must "become situated within the teachers' working contexts" (du Plessis and Webb 2012:48). Similarly, in their study, Yoon et al. (2004) showed that grouping a large number of teachers to develop are not always effective especially if teachers have very specific needs as was found in this study. The need for greater specificity to guide practice is the consensus that PD should be "school based" or "integrated into the daily work of teachers" (Hawley and Valli 1999; Joyce and Showers 2002). Such PD typically requires that a coach or mentor work with teachers on a one on one basis, which is among the most expensive approaches to PD available.

The purpose of this paper was then to describe how these teachers experienced teaching using the intervention program developed by the project team, with a view to expanding this program to other teachers in the IT discipline. This study examined how problem solving techniques in a programming professional development $(\mathrm{P}$ PD) programme helped teachers prepare for teaching within the curriculum. Because one of the goals of the P PD was to help teachers teach programming effectively, it is critical to understand how well the P PD program achieved its goal. To address this purpose, the researchers asked three research questions:

1. Which P PD activities did teachers find useful in helping them?

2. How well did the P PD prepare teachers for teaching practices?

3. What impact did this program (P PD) have on teachers? 


\section{METHODOLOGY}

\section{Context}

Teachers from previously disadvantaged schools located in North West Province and KwaZulu Natal were requested to participate in the professional development programme. Three strategies, problem solving activities, pair programming and a metacognitive approach to problem solving were developed and work-shopped with each teacher separately. The project team members visited each school and work-shopped the strategies individually with the teachers. Although, these strategies were introduced and work-shopped in different phases; one at a time - at least six weeks apart- they are not mutually exclusive; all three are interconnected and can be used together for optimal effect in teaching and learning programming as the learner gains confidence in these strategies. For each of the strategies, a pre-test and post-test was administered to learners, a handbook was prepared, together with exercises for completing, and charts for display if quick access to the strategy is needed. Teachers were interviewed after each strategy was implemented in the classroom.

\section{Participants}

Learners from six classes from six different schools from two provinces in South Africa participated in the project "Empowering IT Teachers in Economically Deprived Rural Schools". A total of 96 learners and six teachers participated in the project. Towards the later part of the project, one teacher excused himself from the program due to personal reasons.

\section{Data Collection Techniques}

\section{Interviews}

Semi- structured interviews were conducted with each of the six teachers. Prior to the intervention programme, interviews were conducted to determine the needs of the teacher, school and learners. Thereafter, interviews took place after each intervention strategy was implemented to determine teachers' views and experiences with the strategy. In addition to these interviews, a wrap up interview was carried out to determine overall experiences of teachers. In the need analy- sis interview, some of the questions asked were as follows:

Are there certain sections in the IT curriculum that you find challenging? (if yes) What are they? Are there certain sections that the learners struggle with? (If yes) Name some of them. Why do you think they struggle with this aspect?

Describe how you go about preparing your lessons in programming. How do you go about introducing a new programming concept?

Is the school fully equipped with a computer room?

In the wrap up interview, some of the questions asked were as follows:

What was positive about the development programme / process so far? (What did you like?) What was the most useful strategy? Would you like to continue with this programme? Do you think other teachers will find this programme useful? Are learners achieving better results?"

\section{Reflective Journals}

Teachers were asked to keep a journal (a blank booklet was provided for the teachers) in which they recorded their lesson activities regarding the implementation of the different strategies used as each lesson progressed. Their challenges, frustrations, successes of the lesson and of students responses were recorded in these journals.

\section{Questionnaires}

For each strategy, a pre- and post- test was designed in the form of a questionnaire for the learners. In addition to the demographic details elicited, a programming task was given in the pre-test, in the post-test learners were asked to solve a similar task using the guidelines and steps taught for each strategy respectively. In each of the tasks given the questionnaire consisted of questions that allowed us to examine their thinking processes, which was invaluable to the overall programme.

\section{Data Analysis}

The data was examined for themes and patterns which might have implications for both theory and practice. Validity or trustworthiness was addressed by using multiple sources of evidence and attempting to establish a chain of evidence (Cohen et al. 2007). While the findings 
cannot be generalized to other population groups and contexts, moderate inferences can be made to similar situations (Patton 2002).

\section{RESULTS}

On examination of the data, five main themes emerged. These themes are elaborated below and reference made to previous research which the respondents intuitively supported. In order to reflect the responses of different teachers, excerpts from teachers are denoted by T1, T2, T3, T4 and T5 at the end of the excerpts.

\section{Handbooks and Resources}

The appreciation of well documented handouts was mentioned in the journals, affirming the importance of resources and handbooks emphasized by Hodgkinson-Williams(2005). It served as a source of confidence for teachers to continue with the work-shopped pedagogy; they had these resources to fall back on. This perceived dependence on the resources became evident when participants stated,

"I think you were very supportive, because I was using your resources to introduce and also to teach. Maybe if you go back to the first strategy, you managed to bring some activities, now second pair programming you also managed to bring me a cd, so that I can sell the idea of pair programming to my learners. And also here the last one you have a questionnaire, it was assisting learners to implement and apply metacognitive skills. So I think your resources were very useful." [T1]

"You have necessary support resources, so I think if you use what you have it is more than enough." [T2]

"It has really benefited us. All the resource material which I got here and all the interviews and the time, all of it really benefited us and I think also the students they are going to do programming well if they follow all these strategies"[T3]

Many learners as well appreciated the guidance provided by the handbook as indicated in the quotation below.

Yes, the problem-solving activities help us because along side there is a set of tools and guidelines that you can use and apply that will help you to solve problems and further develop solving skills.

\section{Continuous Support}

Teachers were appreciative of the support given to them. They felt that it benefitted the learners. No doubt it benefitted them as well because their skills improved. Teachers noted that the support should continue because it is different from other subjects; it is a novel way of learning to program and problem solve. Their sentiments are echoed in the quotation below:

I think you should continue, because IT is a unique subject, you know, learning and teaching strategies in IT are different, this compared to other subjects. So learners can be competent if you compare this in a theoretical performance is different than their practical knowledge. So I think we need support, especially with the practical part of the subject for learners and teachers, so at least we are more equipped to assist our learners. [T1]

Another teacher said, learning is an on-going process, so I am willing to go further and to research further and see. It is not a problem that one. [T2]

The demand for continuous support is further emphasized in the following excerpts:

"You must go on, I think definitely because it has worked for me. I think even next year learners will still enjoy, because we have only started, next year they will get used to it and it will be more productive to them, because this year it was just an introduction and a start, so I think it will be more much easier next year." [T3]

"Yes definitely, there are some workshops maybe once in two terms there are some workshops like that, it is going to definitely benefit them."[T4]

"Yes they will benefit a lot from the strategies. I think it would be much better for the university and the researchers to continue to use these strategies."[T5]

In addition to the teachers' plea for continuous support, learners were also positive regarding the support given by the teachers.

Yes, the problem solving activities (provided by the teacher) supports me when solving a programming problem because it helps me to understand and know what I am solving correctly.

The above views from teachers are in keeping with the study done by Lawless and Pellegrino (2007), emphasizing the need for continuous PD support. 


\section{Useful Strategies}

The problem solving activities was considered most beneficial by the majority of teachers. Some of the reasons given were: assisted with understanding scenarios, learners were able to move ahead with tasks and long term benefits in the practical examinations. IT is presently taught using a scenario-based approach which is recommended by the National Curriculum Statement as documented by the National Department of Education (Department of Education 2007). Often the assessments are based on different scenarios. Teachers' felt that the steps used in problem solving helped learners to unpack the scenarios and thus analyse questions and solve problems based on scenarios. Teachers also felt that they acquired strategies for teaching programming since this includes problem solving activities.

Pair programming was also considered very beneficial and this was mainly due to learners being able to support each other and thereby reducing the demands on teacher; "Yeah they can now share information and support each other. So they can communicate with each other on the same level, share, solve the problems without me running around."[T1]

Because of the time constraint in implementing the third strategy, the metacognitive approach to problem solving, some teachers were not able to observe its full potential. Different schools had logistical problems in completing each aspect within the given time-frame. This constraint is suggested by the excerpts below:

So I think because of the time factor I can say it is metacognition [that was least useful] [T3]

Yeah, very useful, because for example the pair programming one, they get less bored in class. [T4]

I think they go together, all of them they connect. They connect to one another [T4]

Problem solving, that is the strategy that I feel the learners they mastered well in terms of getting the steps that are involved, I think that was the best one.Excluding the metacognition, because we haven't had enough time, so I am not able to compare with the metacognition. [T5]

The strategies proved useful to the learners as well. Some excerpts from learners indicate this:

The experience you get is that you can do these problems and you will attempt other prob- lems knowing that you can or you are able to solve the problems on your own without any help from the teacher or other students.

Problem-solving activities are helpful tools, especially when the teacher assists us. Also we are individually able to logically design an algorithm for any problem we have in programming. Breaking up our solutions step-by-step help develop our analysis skills and our understanding.

\section{Active Learning}

The participants indicated that what they valued of the current programming pedagogies [strategies] were the fact that they were actively involved; both the teacher and the learners were learning. This became evident in responses such as,

"It was two-way, I was learning with my learners while I was implementing this"[T1]

"Yeah, all of them, because it was an opportunity to actively involve learners. So it was good to experiment and to implement them. So I think they have learned a lot... even me"[T2]

In actively learning, collaboration emerged as an important aspect of the learning process. Collaboration is posited as an effective means to solve problems in programming (Thomas et al. 2010). This collaboration is reflected in what one of the teachers said,

"They get to talk to each other in an informal manner and that is when they start to learn. If it is too formal they get bored. And then for the metacognition, their problem solving skills, if they follow the steps, it is easier for me to be able to break things down. They learn better like this, than if I just tell them something..., they catch on fast, because they have sort of have had experience of that thing. The real experience; not just me telling them"[T4]

The teachers felt that the strategy was practical and they could implement it and experience the success. The "hands-on" was important for experiencing success.

Okay, this idea of pair programming, it was wonderful to implement it and see how you can do it, because it was difficult to introduce pair work in programming, so I think that concept it was very useful[T1]

The learners enjoyed the active participation in the learning process as indicated below:

In the IT class working in pairs help so much, because you help and share many things... and 
it makes you too to understand better than you were preciously and it helps .....to ask questions to your partner when not understanding

\section{Challenges Faced}

Some of the major challenges faced were:

- limited time to complete the practical aspects in a single period as stated by one of the participants,

"I feel the time given for the learners to do programming in the class is very less, because we have only one period in each day, that means 45 minutes, they come here and by the time they start doing the program, it is almost over" [T3]

- Assessments were found to be one of the difficult tasks for teachers to develop.The excerpt from a teacher's interview follows: "I don't know if this answers the question, but the thing of assessment, I think the assess [assessment] paper sometimes it doesn't serve a lot of purpose to understanding the class[in Object Oriented Programming - OOP]. I understand that is part of the content that they are supposed to know. But you know what sometimes they will ask you a question based on one thing that is possible that they wouldn't be able to know this, now the whole paper is based on it. If they cannot apply the steps they do not get those marks. "[T4]

While teachers experienced challenges of logistics of time for implementation and assessment, learners experienced challenges of a different nature which was positive in the long term:

I find them rather challenging but I like challenges because out of these problem solving activities I also gain more experience.

\section{DISCUSSION}

The main themes and ideas that were generated in this study were those of availability of handbooks and resources; continuous support; useful strategies; active learning and challenges faced. These will be discussed with a view to answering the research questions.

Findings of this study indicate that the programming professional development (P PD) programme had an impact on teachers and their perceptions of their abilities to teach programming more effectively. The following impressions were gleaned from the emerged themes.

To answer the first question posed in order to guide this research, problem solving and pair programming were considered most beneficial and useful by the participating teachers. Many reasons were given for the enjoyment and success they experienced. Some of the reasons are repeated here specifically with regard to problem solving activities: assisted with understanding scenarios, learners were able to move ahead with tasks and long term benefits in the practical examinations.

It is not surprising that the learners were also very enthusiastic about these approaches. Learners were able to share and gain knowledge from their partners. The following excerpts from learners' descriptions given in the questionnaires regarding pair programming confirm their enthusiasm:

Because when working with someone you understand things better, because you will explain to one another where one don't understand

My partner comes with some skills that I have never had before to solve the problem easily

The third strategy, the metacognitive approach to problem solving was considered the least beneficial. Teachers' felt that the implementation of the metacognitive approach to problem solving was time-consuming and learners were not keen on spending time recording their thinking process. There was also the issue of limited time to implement the metacognitive approach as well as the lack of experience with metacognition on the part of the teacher. It was evident from one teacher's comments that the teacher himself was not clear as to the need for metacognition "metacognition was used with difficult examples"

Interestingly, even though each strategy was introduced separately, teachers discovered for themselves that all 3 strategies are actually interdependent. When asked what was least useful, one teacher commented, "they all go hand in hand", another commented that "for next year I will infuse the strategies from the beginning" and another, "they are tried and tested now, will introduce early in the year".

To answer the second question posed in this study the researchers asked teachers "what they would do differently next year?" Teachers' responses were consistent in that they felt that the change they will make is to introduce strategies earlier in the year, infuse the strategies; that is, they will not do them separately, and possibly pay more attention to grouping differently in pair programming for maximum benefit. These teach- 
ers certainly seemed prepared for the classroom as they gained confidence in their programming to make changes.

In general, time required to complete practical work that includes programming in a single period was highlighted as a challenge, which is a logistical problem related to the school dynamics. Also of importance is the design of assessments regarding OOP. Teachers needed more clarity and guidance with this aspect of teaching. More specifically, challenges mentioned by teachers centred on the use of the metacognitive approach to problem solving. Much of this had to do with the shortage of time to fully implement the approach as well as the limited knowledge that teachers still had on metacognition.

To answer the third question, teachers were emphatic that support should continue because they have learned a lot. "It was two-way, I was learning with my learners while I was implementing this". It is clear that the programme has given them additional subject knowledge in addition to pedagogical programming knowledge to a great extent. More specifically, findings derived from a study of the same project (Govender et al. 2012) showed that these teachers' and learners' self-efficacy in programming improved after the explicit instruction of problem solving activities. The overall findings of this study indicate that programming professional development (P PD) programme had a positive impact on teachers and their perceptions of their abilities to teach programming more effectively. The P PD programme certainly had a positive impact on both teachers and their learners. This positive impact is illustrated by the commitment of teachers to continue with this pedagogy in the following year as suggested in the following excerpts: "tried and tested and it works for me and the learners", "learners are going somewhere now", "improved results of learners", "learners know how to tackle a problem".

\section{CONCLUSION}

Given the challenge to support IT teachers, this study described the support given to IT teachers on a one on one basis. It is generally accepted that intensive, sustained, job-embedded PD focused on the content of the subject that teachers teach, is more likely to improve teacher knowledge, classroom instruction, and student achievement The analysis and results of this study strongly support previous findings as mentioned above in the discussion. The researchers believe that the programming professional development (P PD) programme developed in this project, matched the core principles required for an effective PD programme as suggested in other studies, that is, content focus, active learning, sustained duration, coherence and collective participation.

Furthermore, the researchers believe that three key characteristics, active learning, coherence, and sustained duration which have been espoused to be promising best practices in PD have been met in our P PD programme.

In this study the researchers choose to focus on the one-on-one approach to PD. While this form of PD may not be as cost-effective as other forms of PD, the researchers believe that this form of PD was effective given the mitigating factors mentioned earlier with regards to IT specifically. The PD programme was school based and was integrated into the daily work of the teacher. The researchers trained teachers firstly on how to introduce problem solving, pair programming and a metacognitive approach to problem solving into their classroom. The results were positive as was shown by the demand for continuous support and the improvement in self-efficacy from work done in this project. The intention of the PD programme was achieved - improved teacher learning, improved classroom practice, and improved student learning. The researchers hope that we will be able to continue this form of PD, extending it to more schools and teachers.

\section{ACKNOWLEDGEMENTS}

This research is based on work financially supported by SANPAD. Any opinion, findings and conclusions or recommendations expressed in this material are those of the authors; SANPAD does not accept any liability in this regard.

\section{REFERENCES}

Askar P, Davenport D 2009. An investigation of factors related to self-efficacy for Java Programming among engineering students. Turkish Online Journal of Education Technology, 8(1): 26-32.

Avalos B 2011. Teacher professional development in teaching and teacher education over 10 years. Teaching and Teacher Education, 27: 10-20.

Cohen L, Manion L, Morrison K 2007. Research Methods in Education. London: Routledge. 
Department of EducatioN 2007. Guidelines for Teacher Training and Professional Development in ICT. From $<$ http://www.thutong.doe.gov.za/ResourceDownload. aspx?id=35998 $>$ (Retrieved July 2012).

Desimone L 2009. Improving impact studies of teachers' professional development: Toward better conceptualizations and measures. Educational Researcher, 38: 181-199.

Downes T, Looker D 2011. Factors that influence students' plans to take computing and information technology subjects in senior secondary school. Computer Science Education, 21(2): 175-199.

du Plessis A, Webb P 2012. A teacher proposed heuristic for ICT professional teacher development and implementation in the South African context. The Turkisk Online Journal of Educational Technology, 11(4): 4655.

Gal-Ezer J, Stephenson C 2010. Computer science teacher preparation is critical. ACM Inroads, 1(1): 61-66.

Glazer E, Hannafin M, Song L 2005. Promoting technology integration through collaborative apprenticeship. Educational Technology Research and Development, 53(4): $57-67$

Govender I 2007. Experiences of learning and teaching problem solving in computer programming. African Journal of Research in Science Mathematics and Technology Education, 11(2): 39-50.

Govender I, Govender D W 2012. A constructivist apporach to teach a programming course: Students' responses to the use of a LMS. African Journal of Research in Mathematics, Science and Technology Education, 16(2): 238-252.

Govender I, Govender D, Havenga M, Mentz E, Breed B, Dignum F, Dignum V 2012. Increasing self-efficacy in learning to program: Explicit instruction for problem solving. Acta Academica, (in press).

Harris K R, Love K L, Graham S, Driscol S A, Brindle M, Schatschneider C 2012. Practise-based professional development for self-regulated strategies development in writing. Journal of Teacher Education, 63: 103-119.

Hasni T, Lodhi F 2011. Teaching problem solving more effectively. SIGCSE Bulletin Inroads, 2(3): 58-62.

Hawley W, Valli L 1999. The essentials of effective professional development: A new concensus. In: $\mathrm{G}$ Sykes, L Darling-Hammond (Eds.): Teaching as the Learning Profession: Handbook of Policy and Practice. New York: Teachers College Press, pp. 127150.

Hinson J, LaPrairie K, Heroman D 2006. A failed effort to overcome tech barriers in a K-12 Setting:What went wrong and why? International Journal of Technology in Teaching and Learning, 2(2): 148-158.

Hodgkinson-Williams C 2005. Dust on Keyboards:Policy Gaps in the Integration of ICT into the South African Curriculum. Proceedings of the $8^{\text {th }}$ IFIP World Conference on Computers in Education, 4-7 July 2005. University of Stellenbosch, Stellenbosch.

Horsley S L, Stiles K E, Mundry S, Love N 2010. Designing Professional Development for Teachers of Science and Mathematics. $3^{\text {rd }}$ Edition. United Kingdom: SAGE Ltd.

Ismail M N, Ngah N, Umar I 2010. Instructional strategy in the teaching of computer programming: A need assessment analyses. Turkish Online Journal of Educational Technology, 9(20): 125-131.

Joyce B, Showers B 2002. Student Achievement Through Staff Development. Alenandria: VA: Assosciation for Supervision and Curriculum Development.

Lawless K, Pellegrino J 2007. Professional development in integrating technology into teaching and learning: Knows, unknows, and ways to pursue better questions and answers. Review of Educational Research, 77(4): 575-614.

Marrongelle K, Sztajn P, Smith M 2013. Scaling up professional development in an era of common state standards. Journal of Teacher Education, 64: 202-211.

Mentz E, Bailey R, Havenga M, Breed B, Govender D, Govender I, Dignum F, Dignum V 2012. The diverse educational needs and challenges of information technology teachers in two black rural schools. Perspectives in Education, 30(1): 70-78

Paik S, Zhang M, Lundeberg M, Eberhardt J, Shin T S, Zhang T 2011. Supporting science teachers. Journal of Science Education Technology, 20: 422-434.

Patton M 2002. Qualitative Research and Evaluation Methods. Thousand Oaks, London: SAGE.

Saeli M J, Perrent W, Jochens Zwaneveld B 2011. Teaching programming in secondary school: A pedagogical content knowledge perspective. informatics in education. Informatics in Education, 10(1): 73-88.

Smith M S 2009. Practice- based Professional Development for Teachers of Mathematics. United Kingdom, SAGE Ltd.

Thomas P, Fernández R, Manjón B 2010. Learning teamwork skills in university programming courses. Computers and Education, 53(2): 517-531.

Yoon K, Jacobson R, Garet M, Birman B, Ludwig M 2004. Professional Development Activity Log (PDAL): A New Approach to Design, Measurement, Data Collection and Analysis. April 2004, Paper Presented at Annual Meeting of the American Educational Research Association. San Diego, CA. 